\title{
Física Filosófica
}

Philosophical Physics

Luiz Maurício Bentim da Rocha Menezes ${ }^{1}$

\section{RESUMO}

Expomos o trabalho em andamento no projeto de extensão "Física Filosófica", que tem o intuito de desenvolver a formação de alunos do Instituto Federal de Educação, Ciência e Tecnologia do Triângulo Mineiro, assim como o público externo que tenha interesse no âmbito da interdisciplinaridade e em diferentes assuntos. A parte que apresentamos aqui foi desenvolvida nos anos de 2018 e 2019 e colocamos os resultados neste trabalho. A metodologia que utilizamos para o desenvolvimento deste projeto consiste na apresentação de uma série de palestras como temáticas diferentes que relacionem as disciplinas de humanidades, exatas e biológicas, levando ao aperfeiçoamento dos participantes nessas áreas.

Palavras-chave: Projeto de Extensão. Filosofia. Interdisciplinaridade.

\begin{abstract}
We expose the work in progress in the Philosophical Physics, an extension project that aims to develop the training of students at the Federal Institute of the Triângulo Mineiro, as well as the external public that is interested in the scope of interdisciplinarity and in different subjects. The part that we present here was developed in the years 2018 and 2019 and we put the results in this article. The methodology we use for the development of this project consists of the presentation of a series of lectures as different themes that relate the disciplines of humanities, exact and biological sciences, leading to the improvement of the participants in these areas.
\end{abstract}

Keywords: Extension project. Philosophy. Interdisciplinarity.

\section{INTRODUÇÃO}

O projeto de extensão Física Filosófica nasceu de uma iniciativa entre dois professores, um de filosofia e outro de física, com o intuito de explicar aos alunos do Instituto Federal de Educação, Ciência e Tecnologia do Triângulo Mineiro (IFTM), Campus Uberaba, as relações interdisciplinares entre as duas disciplinas. Posteriormente o projeto foi crescendo, ganhando visibilidade fora da instituição, com participantes externos e acréscimo de novos professores ao projeto.

\footnotetext{
${ }^{1}$ Doutor em Filosofia pela Universidade Federal do Rio de Janeiro, Brasil; estágio pós-doutoral na Universidade do Estado do Rio de Janeiro, Brasil; professor efetivo do Instituto Federal do Triângulo Mineiro, Minas Gerais, Brasil (lmbrmenezes@yahoo.com.br).
} 
A metodologia que utilizamos para o desenvolvimento deste projeto consiste na apresentação de uma série de palestras como temáticas diferentes que relacionem as disciplinas de humanidades, exatas e biológicas, levando ao aperfeiçoamento dos participantes nessas áreas.

A partir do Mito de Prometeu, o projeto tem o intuito de investigar a aporia, posta por Epimeteu, sobre a humanidade e a solução de Prometeu através do roubo do fogo e da arte (téchne) divinos. A palavra aporía pode ser mais bem entendida se for dividida no prefixo de negação "a" e a palavra póros que significa "passagem, caminho ou recurso". Aporía seria, portanto, "sem passagem" ou "sem recurso".

A aporía é um elemento de perplexidade que impulsiona a filosofia a buscar soluções para as suas questões, sendo um desafio imposto ao filósofo. No caso desse mito, a aporía se resolve no ensino das téchnai aos homens, o que faz de Prometeu um filósofo divino capaz de abrir a passagem, dar o recurso, o póros, à humanidade, mesmo que sua atitude tenha o condenado aos grilhões inquebrantáveis de Hefesto. Será essa mesma atitude prometeica do homem pelo avanço da ciência e das artes, que levará à gênese do Prometeu Moderno e também a sua condenação.

Prometeu, dessa forma, pode ser reconhecido como o primeiro humanista, pois se condenou para salvar a humanidade de forma irrestrita. A filosofia, já diziam os antigos, começa com o espanto, com o questionar-se sobre o mundo. Sem questão não há filosofia e toda questão leva a um impasse a ser resolvido. O homem que filosofa é um homem que se move na dificuldade de resolver uma questão, de pensar sobre os caminhos possíveis a serem percorridos no intuito de se encontrar uma resposta adequada para o impasse. No entanto, o filósofo é somente aquele que se adianta sobre o problema ou aquele que se dedica a resolver o problema, pois a aporía pertence ao próprio sentido do humano. Prometeu através da sua ação para com os homens, vem aproximar a humanidade da dádiva divina e nos permitir a abertura do caminho. Aberto o caminho, estamos livres para escolher nosso próprio percurso perante a aporía da vida. Esse projeto tem o intuito de estudar as várias faces do humanismo a partir das leituras existentes sobre o mito de Prometeu.

\section{Discussão teórica}

O mito do Prometeu trata do humano e é do humano que queremos falar. Quando Protágoras resolve contar um mito para expor a sua visão sobre a virtude política, ele nos dá indícios do 
que é propriamente o humano. O mito do Prometeu contado no Protágoras de Platão ${ }^{2}$ fala sobre a gênese dos seres vivos e do encargo dado por Zeus a Epimeteu e Prometeu. Eles deveriam distribuir as capacidades $[\delta v v \alpha ́ \mu \varepsilon 1 \varsigma]^{3}$ a todos os seres de maneira que todos pudessem sobreviver no mundo. Epimeteu se encarrega da distribuição e parece dar conta do recado, fazendo isso na devida proporção. No entanto, não sendo muito sábio, acaba usando todas as capacidades antes que chegassem no homem. Isso leva Epimeteu a um impasse

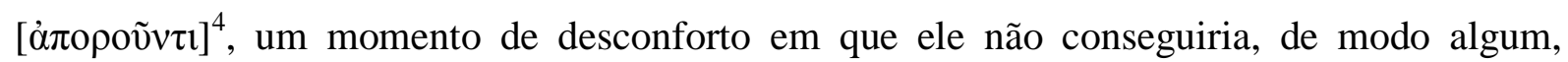
resolver esse problema. Prometeu chega justamente nesse momento de aporía em que o homem estava fadado a perecer quando despertasse, devido à má distribuição feita por Epimeteu das capacidades, cabendo a Prometeu resolver o impasse posto pelo irmão. Sem mais nenhuma capacidade para dar ao homem, Prometeu se vê obrigado a roubar dos deuses o fogo e as artes e a entregá-los aos homens. Graças ao feito de Prometeu que o homem pôde sair da aporía e ser capaz de sobreviver no mundo. Prometeu é, portanto, aquele que fez o

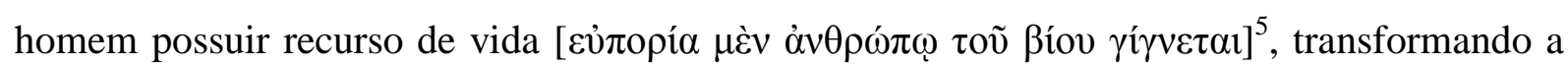
aporía em euporía. Por esse feito, Prometeu será, depois, condenado e castigado por Zeus e será acorrentado no Cáucaso por Hefesto.

A aporía é um elemento de perplexidade que impulsiona a filosofia a buscar soluções para as suas questões, sendo um desafio imposto ao filósofo. No caso desse mito, a aporía se resolve no ensino das téchnai aos homens, o que faz de Prometeu um filósofo divino capaz de abrir a passagem, dar o recurso, o póros, à humanidade, mesmo que sua atitude tenha o condenado aos grilhões inquebrantáveis de Hefesto.

O que queremos atentar com o mito aqui exposto é para o sentido da aporía e sua importância para o filosofar. E é nesse sentido que vem simbolizar Prometeu, aquele que pensa antes e se adianta sobre todos os outros. A aporía se encontra no escolher, no como viver, no que fazer da vida que nos foi dada. Será através do fogo da razão e do uso das artes e técnicas que o homem irá se aprimorar e avançar dentro das suas próprias capacidades e possibilidades na tentativa de se descobrir como humano, pois não há humano que possa se manter fora da dádiva que nos foi entregue. Prometeu nos permite escolher nosso próprio caminho a partir do percurso da vida.

\footnotetext{
${ }^{2}$ Utilizamos a edição traduzida e organizada por Daniel Lopes (Perspectiva, 2017). Demais citações serão abreviadas por Prot.

${ }^{3}$ Prot., $320 \mathrm{~d} 5$.

${ }^{4}$ Prot., $321 \mathrm{c} 3$.

${ }^{5}$ Prot., 321e3-322a1.
} 
No Prometeu Acorrentado, de Ésquilo, podemos ver como, apesar de agrilhoado e sem liberdade para agir, Prometeu mantém-se a frente em sua visão, sendo que o próprio destino de Zeus depende da liberdade de Prometeu (ÉSQUILO, 1993, v. 1.003-4). E nisso, Prometeu desafia Hermes, mensageiro de Zeus:

Fica sabendo ainda: nunca eu trocaria minha desdita pela tua submissão.

Acho melhor ficar preso a este rochedo que me ver transformado em fiel mensageiro de Zeus, senhor dos deuses! Assim mostrarei aos orgulhosos quão vazio é seu orgulho! (ÉSQUILO, 1993, v. 1.283-8).

Prometeu mesmo acorrentado se diz mais livre que Hermes na sua função de submisso mensageiro de Zeus. A liberdade de Prometeu consiste na sua métis, sua astúcia, sua inteligência, isto é, no seu livre pensar que é fruto do seu saber, que o faz sempre estar adiante dos demais. O orgulho do liberto Hermes é vão, pois ele está preso na própria ignorância e não tem como saber, e nem mesmo arrancar, o que diz Prometeu saber. Prometeu é resiliente perante as circunstâncias em que se encontra quando foi acorrentado por Hefesto. A tentativa de intimidá-lo pelo poder das sentinelas de Zeus, Krátos e Bía, de nada adiantou para anular a perspicácia e a coragem de Prometeu frente ao seu destino. Ele se mantém firme e paciente perante a força onipotente e opressora de Zeus. Nesse sentido, Prometeu e Sócrates, tragédia e filosofia, parecem ligados ou acorrentados por princípio (NASS, 1995), Prometeu no seu saber adiante, Sócrates pelo seu saber que nada sabe. Ambos firmes perante o verdadeiro saber.

A obra cartesiana é um marco para o estabelecimento do pensamento moderno e terá ampla repercussão entre seus pares. Seu método consiste em primeiro negar por meio da dúvida para depois construir os alicerces pelos quais se sustentará toda a sua filosofia, retomando, assim, a possibilidade de se conhecer algo. Iremos expor brevemente seus argumentos para que possamos entender a relevância de seu método para o desenvolvimento do modus operandi do pensamento moderno. Descartes inicia o processo como um cético tendo o seguinte princípio axiomático: tudo que alguma vez me enganou é falso. Seguindo isso, ele desenvolverá três argumentos: (i) argumento dos sentidos; (ii) argumento do sonho; (iii) argumento do gênio maligno (DESCARTES, 1979).

No primeiro argumento, Descartes coloca em dúvida todos os sentidos humanos, tomando a experiência como fruto do engano. No segundo argumento, ele fará um paralelo entre o sonho 
e a realidade. Enquanto sonhamos cremos estarmos fazendo o que sonho determina e não temos consciência que estamos dormindo. Dessa forma, não podemos ter certeza que estamos realmente acordados ao invés de dormindo. O argumento do sonho coloca em dúvida o mundo e sua realidade física. No terceiro argumento, Descartes irá supor a existência de um ser mais poderoso do que eu, um ser que ele chamará de gênio maligno. O gênio maligno é uma criatura que tem por função me enganar toda vez que eu penso. Dessa forma, Descartes coloca em dúvida a realidade matemática. Esses três argumentos são fundamentais para que ele permaneça na dúvida e suspenda o juízo momentaneamente.

A guinada para o conhecimento se dará a partir da dúvida. Na retomada de suas reflexões, Descartes chegará à primeira verdade: eu penso. É decorrente disso a famosa frase: eu penso, logo existo [ego cogito ergo sum] que se encontra presente em sua outra obra $O$ Discurso do Método. Essa é uma verdade necessária no pensamento cartesiano, pois será a partir da formulação dessa verdade que Descartes poderá decorrer todas as outras verdades como Deus, a matemática, o mundo e a realidade corpórea. Esse é o ponto que queríamos chegar com a exposição da filosofia cartesiana. A descoberta do cogito é um paradigma para a constituição da modernidade. Uma modernidade que parte do indivíduo, de um eu subjetivo para conhecer e julgar o mundo. A realidade do cogito é também uma separação, pois eu nada posso saber do mundo tomando o pensamento como meio, o que faz do meu processo de conhecer as coisas indireto. Não bastasse isso, a modernidade estabelece uma ruptura com a natureza, formulando uma concepção de mundo mecanicista da qual somo herdeiros diretos.

E aqui nos propomos a relacionar Filosofa e Literatura no seu mais amplo sentido. Pois a aporía que está posta em toda questão filosófica, em toda obra aberta que há em todas as obras filosóficas, também pode ser vista nas obras literárias como em Kafka, Joyce ou Baudelaire, por exemplo. E se tomarmos ainda o Prometeu Desacorrentado, de Percy Shelley, veremos um Prometeu liberto ou, se me permitirem a livre interpretação de unbound, “ilimitado". Nas palavras de Shelley, nos diz um ainda acorrentado Prometeu, mas firme em seu desígnio:

Três mil anos de insone desabrigo, momentos, sempre por ferrões divisos, iguais a anos, tortura e solitude, desdém e desespero - eis meu reino mais glorioso que aquele que em teu trono despiciendo prospectas, Grande Deus! Ah, onipotente, se eu me rebaixasse à tua vergonhosa tirania 
e não pendesse fixo a este gélido

morro confunde-águias, negro e morto;

sem fim, sem mato, inseto, besta ou vida.

Ai de mim! Dor, dor, sempre, sempiterna!

Sem mudar, sem cessar, sem crer! Resisto.

(SHELLEY, 2015, v12-24).

A resistência de Prometeu perante a tirania de Zeus é o que o mantém livre, pois mesmo na dor e na solidão, ele se mantém sempre adiante no seu livre pensar, naquilo que ninguém antes dele pode conhecer. E aqui já podemos falar de um Prometeu Moderno, que nos versos de Shelley reconstroem o antigo Prometeu, sem mais ser o mesmo dos tempos clássicos.

Se pensarmos que Prometeu trata de um legado deixado aos homens, um legado de fogo e artes, teremos o início de uma resposta, pois será essa mesma atitude prometeica do homem pelo avanço da ciência e das artes, que levará à gênese do Prometeu Moderno e também a sua condenação. E quando falamos de um Prometeu Moderno, não podemos nos esquecer da obra de Mary Shelley, Frankenstein ou o Prometeu Moderno, escrita há mais de duzentos anos. Qual o intuito dela ao relacionar sua obra com o mito de Prometeu?

Se levarmos em consideração a criatura que ganhou vida, podemos ver nela a dor, o exílio e a condenação presentes no mito. No entanto, a nosso ver, não é a criatura que recebe a alcunha de Prometeu Moderno, mas o criador. É o criador que se chama Frankenstein, apesar de erroneamente associarmos o seu nome à criatura. É o criador que se utiliza da máxima arte para novamente roubar o fogo divino e dar vida a algo que ele construiu. Frankenstein roubou algo que pertencia somente à esfera divina, ele infringiu uma regra da natureza que dizia que os seres vivos só seriam gerados através da procriação. Ele rompeu essa regra e deu vida a uma criatura construída por ele apenas. Ao fazer isso, ele rompeu irreversivelmente com Deus e se tornou ele mesmo um deus na sua atitude criadora e vital. Frankenstein na sua ousadia divina acabou por condenar a si mesmo aos seus próprios grilhões:

Por um momento, minha alma elevou-se acima de seus temores degradantes e miseráveis para contemplar as ideias divinas de liberdade e sacrifício de que aqueles lugares eram os monumentos e recordações. Por um instante, ousei romper meus grilhões e olhar ao redor com um espírito livre e elevado, mas o ferro corroera-me a pele, e eu afundei novamente, trêmulo e desesperado no miserável eu. (SHELLEY, 2002, p. 67-68).

Sem Deus para se agarrar, o próprio homem ser torna deus e, como isso, prisioneiro de si mesmo e do seu próprio pensar. Será preciso fazer um resgate do humanismo por meio do 
existencialismo presente na obra de Sartre e sua inversão da metafísica humano em que "a existência precede a essência" (SARTRE, 1973, p.11).

\section{Execução do projeto}

O "Física Filosófica" é um projeto de extensão que tem por intuito apresentar uma série de palestras que relacionem, prioritariamente, as disciplinas de física e filosofia. No entanto, o projeto acabou ganhando força e ganhou novos integrantes de outras áreas, o que aumentou ainda mais o nicho interdisciplinar do projeto. Nisso, se propõe a fundamentar e complementar as disciplinas nos seus quesitos interdisciplinares, mas especificamente nas disciplinas que acompanham.

O projeto se justifica pelo modo interdisciplinar de apresentar pontos em comum da física e da filosofia, além de outras disciplinas correlatas. O projeto já apresentou, até o momento, entre os anos de 2018 e 2019, cinco palestras com assuntos distintos e coerentes com a proposta e ainda tem outros projetos para novas palestras nos anos subsequentes. Participam do projeto outros cinco professores do IFTM de áreas distintas da Filosofia: Adriana Nogueira Alves (Astronomia), Cristiane Alvarenga Gajo (Matemática) Felipe Agostini Cerqueira (Antropologia), Renato Soares Capellari (Biologia) e Ricardo Spagnuolo Martins (Física).

A primeira palestra foi realizada em 14 de setembro de 2018 e se intitulou "Filosofia Présoquântica: Anaximandro e a Física". A filosofia, já diziam os antigos, começa com o espanto, com o questionar-se sobre o mundo. Sem questão não há filosofia e toda questão leva a um impasse a ser resolvido. Por isso, resolvemos com essa palestra retomar o problema dos primeiros filósofos, que também podem ser considerados nossos primeiros físicos ou fisiólogos, por serem os primeiros a observarem e buscarem respostas para questões fundamentais a partir da phýsis. Isso acarretou, por consequência, na construção da metafísica grega.

A segunda palestra foi realizada em 05 de outubro de 2018 e se intitulou "Mecânica x Dinâmica: Newton x Leibniz". Nessa palestra, se procurou demonstrar em que a física moderna se diferencia da antiga e como ela foi construída. A diferença entre o pensamento de Newton e Leibniz foi a ênfase da proposta.

A terceira palestra foi realizada em 21 de agosto de 2019 e se intitulou "Magia e Ciência: um debate", em que se procurou mostrar a proximidade da magia e da ciência e o seu progressivo distanciamento ao longo da história. Para isso, se utilizou da noção grega de phýsis, 
phármakon e pharmakis para mostrar como os vocabulários mágico e médico estavam mais próximos na antiguidade, apesar de consistirem em objetivos diferentes. No período moderno, a magia acaba caindo em esquecimento com o aparecimento dos novos métodos de experimentação da ciência.

A quarta palestra, realizada em 16 de outubro de 2019, se intitulou "Evolução: do Alpha Primata ao Alpha Go", em que se discutiu os escritos de Darwin e ascensão da inteligência artificial no mundo moderno. A ideia foi trazer maior proximidade com a teoria da seleção natural e suas consequências para o pensamento moderno.

A quinta palestra tratou dos "Mundos Possíveis" e foi realizada em 27 de novembro de 2019. $\mathrm{O}$ intuito dessa palestra foi discutir as diversas teorias sobre diferentes mundos e suas possibilidades em cada uma das disciplinas dos palestrantes: filosofia, antropologia, matemática, física e astronomia. Desse modo, um leque de possibilidades se abriu diante do público.

\section{CONSIDERAÇÕES FINAIS}

Através desses apontamentos, apresentamos a atividade de extensão desenvolvida pelo projeto "Física Filosófica" do IFTM. O grupo segue em atividade e está desenvolvendo constantemente novas atividades a serem implementadas nos próximos anos junto com alunos, servidores e pessoas da comunidade externa ao campus que queiram participar do projeto.

\section{REFERÊNCIAS}

DESCARTES, R. Meditações. São Paulo: Abril Cultural, 1979. (Coleção Os Pensadores).

DESCARTES, R. Discurso do método. São Paulo: Abril Cultural, 1979. (Coleção Os Pensadores).

ÉSQUILO. Prometeu acorrentado. Tradução de Mario da Gama Kury. Rio de Janeiro: Jorge Zahar Editor, 1993.

HARARI, Y. N. Sapiens: uma breve história da humanidade. Porto Alegre: L\&PM, 2018.

JAEGER, Werner. Paidéia: a formação do homem grego. São Paulo: Martins Fontes, 2003.

LOPES, D. R. N. Protágoras de Platão. Tradução, estudo introdutório, comentários e notas de Daniel R. N. Lopes. São Paulo: Perspectiva; Fapesp, 2017. 
NAAS, M. Philosophy bound: the fate of the Promethean Socrates. Research in Phenomenology, v. 25, p. 121-141, 1995.

ROSSETTI, L. Introdução à filosofia antiga: premissas filológicas e outras ferramentas de trabalho. São Paulo: Paulus, 2003.

PRÉ-SOCRÁTICOS. São Paulo: Abril Cultural, 1973. (Coleção Os Pensadores).

SARTRE, J. P. O existencialismo é um humanismo. São Paulo: Abril Cultual, 1973. (Coleção Os Pensadores)

SHELLEY, M. Frankenstein ou o Prometeu Moderno. Tradução de Adriana Lisboa. Rio de Janeiro: Ediouro, 2002.

SHELlEY, P. B. Prometeu Desacorrentado e outros poemas. Tradução de Adriano Scandolara. Belo Horizonte: Autêntica, 2015.

Submetido em 19 de fevereiro de 2020.

Aprovado em 6 de abril de 2020. 